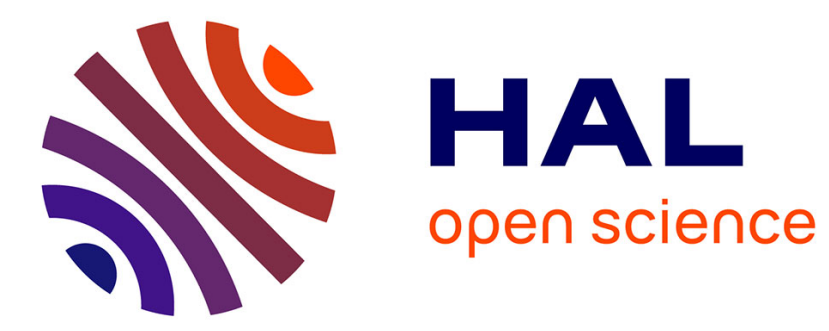

\title{
Gravity study of the Pitcairn-Easter hotline
}

Marcia Maia, G.. A. Dehghani, M Diament, J Francheteau, P Stoffers

\section{To cite this version:}

Marcia Maia, G.. A. Dehghani, M Diament, J Francheteau, P Stoffers. Gravity study of the PitcairnEaster hotline. Geophysical Research Letters, 1994, 21, pp.2527-2530. insu-01354635

\section{HAL Id: insu-01354635 https://hal-insu.archives-ouvertes.fr/insu-01354635}

Submitted on 19 Aug 2016

HAL is a multi-disciplinary open access archive for the deposit and dissemination of scientific research documents, whether they are published or not. The documents may come from teaching and research institutions in France or abroad, or from public or private research centers.
L'archive ouverte pluridisciplinaire HAL, est destinée au dépôt et à la diffusion de documents scientifiques de niveau recherche, publiés ou non, émanant des établissements d'enseignement et de recherche français ou étrangers, des laboratoires publics ou privés. 


\title{
Gravity study of the Pitcairn-Easter hotline
}

\author{
M. Maia1, G.A. Dehghani ${ }^{2}$, M. Diament ${ }^{3}$, J. Francheteau ${ }^{1}$ and P. Stoffers ${ }^{4}$
}

\begin{abstract}
Shipboard free air gravity and bathymetric anomalies with an extension of $400 \mathrm{~km}$ were identified across the Pitcairn-Easter hotline in the South Pacific. The anomalies are associated with one of the positive geoid undulations observed in the area from satellite data. Several smaller topographic features, volcano-tectonic ridges oriented $\mathrm{N} 65^{\circ} \mathrm{E}$, are superimposed on the topographic high. Admittance computations and direct modeling show that the swell topography is compensated by a low density zone within the lithosphere, 4 to $8 \mathrm{~km}$ below the crust The volcano tectonic ridges are locally compensated in a classical Airy sense. The swell and the associated ridges were probably created by the action of a thermal anomaly resulting from the interaction of the Easter Island hotspot and of the Easter Microplate accretion centers.
\end{abstract}

\section{Introduction}

The existence of linear undulations in the gravity field with wavelengths ranging from 200 to $1000 \mathrm{~km}$ over the Central Pacific Ocean is now well established [Haxby and Weissel, 1986; Baudry and Kroenke, 1991; Maia and Diament, 1991; Cazenave et al., 1992]. The undulations are generally associated with volcanic or magmatic features. For example, volcanic chains are located over linear geoid anomalies with wavelengths of 500 to $800 \mathrm{~km}$. Sublithospheric convective rolls [Buck and Parmentier, 1986] were invoked as a source for the anomalies [Baudry and Kroenke, 1991; Maia and Diament, 1991]. This hypothesis could help to explain the deviations from the classical hot spot model shown by several volcanic chains of the area [Bonatti et al., 1976; Turner and Jarrard, 1982; Diament and Baudry, 1987]. Some authors however inferred that mass heterogeneities within the lithosphere were causing the gravity anomalies. Processes at the origin of density anomalies can be boudinage, fractures and associated magmatism or convection (the density anomalies could have been frozen in the ageing lihosphere) [Winterer and Sandwell, 1987; MacAdoo and Sandwell, 1989]. Maia and Diament, [1991] observed that some of these undulations cross the East Pacific Rise at particular points, where Easter and Juan Fernandez microplates are located. A recent study showed that a relationship between the pattern of the anomalies and the ridge segmentation may indeed exist [Calgano and Cazenave. 1993]. Moreover the pattern of geoid anomalies may display, in the same area, both the directions of absolute and of relative plate motions, superposed. It is the case in the North Pacific (J.L. Olivet, pers. comm.) and in the South Central Pacific [Maia and Diament, 1991]. Such a pattern suggests that different sources for the anomalies can exist.

One of the most striking geoid undulations is associated with the Pitcairn-Easter Hotline, which includes the Pitcairn and the Easter hotspots and the Sala y Gomez volcanic chain [Bonatti et al, 1976] (Fig.1). The geoid anomaly has an average amplitude of $50 \mathrm{~cm}$ (in the $25-1500 \mathrm{~km}$ waveband) and crosses the ridge at the emplacement of the Easter Microplate. Between the Pitcairn hot spot $\left(23.9^{\circ} \mathrm{S}-130.8^{\circ} \mathrm{W}\right)$ and the microplate,

1. URA 1278 du CNRS and GDR 910, Brest, France

2. Institut für Geophysik, Unjversität Hamburg, Germany

3. IPG Paris, France

4.Geologisch-Paläontologisches Institut,Universität Kiel, Germany

Copyright 1994 by the American Geophysical Union.

Paper number 94GL01652

0094-8534/94/94GL-01652\$03.00 several volcanic edifices exist. Some of these edifices, such as the Crough Seamount $\left(25^{\circ} \mathrm{S}-122^{\circ} \mathrm{W}\right)$ were found to be part of a system of en-echelon ridges striking roughly $N 65^{\circ} \mathrm{E}$. These ridges are oblique to the accretion directions and to the lithospheric grain and are formed by narrow (20-30 km large) linear features more than $200 \mathrm{~km}$ long, with very abrupt flanks ( $R$. Searle, unpublished data). Volcanic edifices, some higher than $2000 \mathrm{~m}$ above the sea floor, are emplaced on these ridges.

The SO-80 cruise of the FS Sonne, in June/July 1992 aimed a geophysical and petrological study of the Pitcairn-Easter Hotline. As part of the objectives, we carried out a survey of one of these ridges (Fig. 2). Another objective was to verify if the observed geoid undulation could be associated with any particular topographic signal. Three N-S profiles were thus carried out in order to investigate the nature of the geoid highs.

\section{Data and method}

Eighteen ascending and descending SEASAT tracks were used in our analysis. Note that for the wavelengths under investigation more recent data such as GEOSAT would not have improved our results, since the spacing of satellite tracks is equivalent. Also, improvements in the resolution of the altimetric measurements for GEOSAT are more significant for the short than for the medium wavelengths,considered here. Bathymetry along the SEASAT profiles was computed from the DBDB5 data base. We shall keep in mind the poor quality of this data base in the area when analysing the results [Smith, 1993].

Three N-S profiles were carried out during the cruise (Fig. 1a), one continuous, $500 \mathrm{~km}$-long (profile 1) and two about 300 $\mathrm{km}$-long (profiles $2 \mathrm{~A}$ and $2 \mathrm{~B}$ ). The location of the profiles (1, $2 \mathrm{~A}$ and $2 \mathrm{~B}), 10 \mathrm{~km}$ apart, and their orientation were chosen in order to cross one of the en-echelon ridges and to be perpendicular to the general trend of the geoid anomaly. Profiles $2 \mathrm{~A}$ and $2 \mathrm{~B}$ were used to compose a single profile $500 \mathrm{~km}$ long (here called profile 2). In addition, the en-echelon ridge was surveyed by $50 \mathrm{~km}$-long regularly spaced profiles normal to the trend of the ridge (Fig. 2a). Bathymetry and free air anomaly marine profiles 1 and 2 were bandpass filtered using a Butterworth recursive filter of the fourth order. The $200 \mathrm{~km}$ cut-off wavelength was chosen in order to separate the short wavelength component of the signal from a longer wavelength that could be visually identified. The long wavelength residual was obtained by removing the filtered signal from the original non-filtered profile. SEASAT geoid profiles, $5300 \mathrm{~km}$ long, were also bandpass-filtered in order to remove the wavelengths longer than $1500 \mathrm{~km}$ and shorter than $25 \mathrm{~km}$. From these, $800 \mathrm{~km}$ segments, centered over our area, were selected avoiding contribution of other structures to the admittance.

Admittance was computed for the three data sets: the filtered geoid and the synthetic bathymetric profiles, the $500 \mathrm{~km}$ shipboard profiles and the ridge profiles. The experimental points were then compared to theoretical curves calculated for different models. We considered two models of compensation: the classical elastic plate model (the Airy model being an end member case when no rigidity is assumed) and a model where the compensation is achieved by a low density zone in the upper mantle beneath a crust of constant thickness (Airy $I I$ model) [Louden, 1981]. For plate models, four parameters were allowed to vary simultaneously, in a pre-determined range: effective elastic thickness (E.E.T.), crustal thickness, average load density and average depth of the topography. For Airy II models, the E.E.T. is replaced by the depth to the low density zone. Best fits were determined by the minimum rms values. The best fit parameters deduced from the admittance analysis were used to give initial constraints to compute direct gravity models using the Parker [1972] development up to the order 3 . We computed the gravity effects of the topography, of the Moho interface and, in the Airy II model, of an interface materializing the density contrast. Models are one-dimensional, 


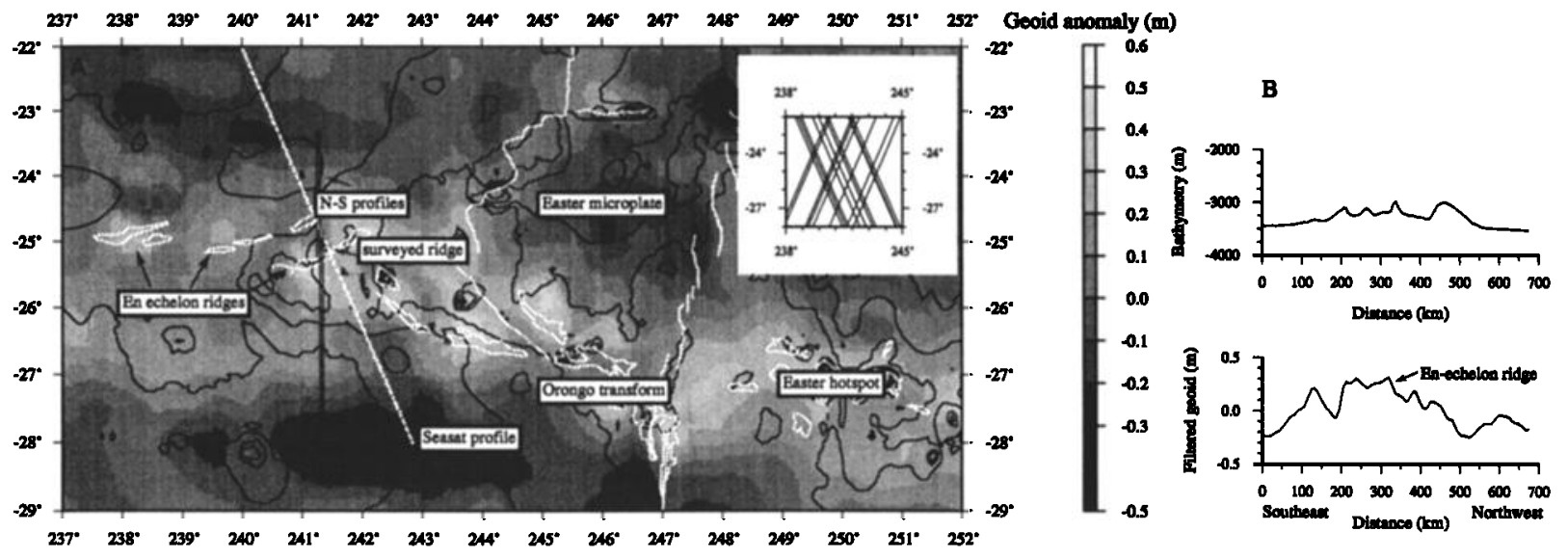

Flgure 1. A DBDB5 bathymetry (black contour lines) superposed to the filtered geoid anomalies (25-1500 $\mathrm{km}$ waveband; gray shades). Thick lines show the emplacement of the SO-80 N-S profiles. The Easter Microplate boundaries and the main topographic trends are shown in white. The grid was obtained using the cubic Bspline method of Inoue (1986) with a grid spacing of $0.25^{\circ}$. Bathymetric contour lines each $1000 \mathrm{~m}$. White dotted line shows the emplacement of the SEASAT profile displayed in B. Inset on top right shows the location of all SEASAT profiles used in our analysis. B Filtered geoid profile $(25-1500 \mathrm{~km}$ waveband) and corresponding DBDB5 bathymetry located in $\mathbf{A}$ The surveyed en-echelon ridge position is shown by the arrow.

but since we are mainly interested in the long wavelengths, this approximation is reasonable. For the short wavelengths, this may underestimate the anomaly and must be considered while interpreting the results.

\section{Results}

Fig. 1b shows one of the SEASAT geoid profiles, filtered in the $25-1500 \mathrm{~km}$ waveband, and the corresponding DBDB5 derived bathymetry. The bathymetic signal of the swell seen on the geoid and on the bathymetric shipboard profiles is very subdued, due to the poor quality of the DBDB5 bathymetry. Fig. 3 shows the bathymetry and free air anomaly for shipboard profiles 1 and 2 , unfiltered, filtered in the $1-200 \mathrm{~km}$ waveband and the residual obtained by removing the short wavelengths from the unfiltered profiles. The short wavelength signal correspond to topographic features such as the volcanic ridges. A broad anomaly $(400 \mathrm{~km})$ can be identified on the residuals as a swell on which the ridges are superposed. The location of this swell corresponds to the positive geoid anomaly (Fig. 1). Fig. 2 displays the en-echelon ridge bathymetry (2a) and free air anomaly (2b). The morphology changes from a central smooth and narrow part to extremes occupied by two large volcanoes (N. Binard unpublished data).

Fig 4 shows the admittance obtained for the filtered geoid and DBDB5 bathymetry (4a), the $500 \mathrm{~km}$ profiles $1-2(4 \mathrm{~b})$ and the profiles over the en-echelon ridge (4c). The lines show the fits for some of the different compensation models considered. Rms for different models are shown in Fig. 5. For the geoid, the poor bathymetry prevents a good analysis, but the best fit (dots and long dashes in Fig. 4a, rms $0.0244 / 0.0247 \mathrm{~m} / \mathrm{km}$ ) corresponds to a plate model with very low effective elastic thickness $(2 \mathrm{~km})$, thick crust $(8 \mathrm{~km})$ and relatively low density loads $\left(2.6 \times 10^{3} \mathrm{~kg} / \mathrm{m}^{3}\right)$. Best fits always correspond to a flexural model with low plate thicknesses. A spectral analysis of the DBDB5 bathymetry was performed to check whether this result might be a consequence of artefacts introduced by the interpolation methods used to create the data set [Smith, 1993]. The amplitude spectrum displayed slopes of -1 for this waveband. Only for a small fraction between 35 and $50 \mathrm{~km}$ slopes were close to -2 , showing a reduction of energy in the signal. Experimental points in this waveband showed very low coherence values and were not considered in the analysis. The better constrained fits for the shipboard profiles 1 and 2 (dots, solid and dashes in Fig. 4b; rms in Fig. 5b) are always obtained for Airy II models with relatively low compensation depths (4 to $8 \mathrm{~km}$ below the crust) a rather thick crust $(8-10 \mathrm{~km})$ and a high load density $\left(2.8 \times 10^{3} \mathrm{~kg} / \mathrm{m}^{3}\right)$. Plate fits require either an unreasonable crustal thickness (14-16 km) or else display a systematic misfit for the long wavelengths. For the en-echelon ridge (Fig. 4c), the fits are of low quality (rms in Fig. 5c), probably due to the small size of the feature. Best fits (dashes in Fig. 4c) are for Airy models with low crustal thicknesses (4-
$6 \mathrm{~km})$ and low density loads $\left(2.4 \times 10^{3} \mathrm{~kg} / \mathrm{m}^{3}\right)$. Higher densities would require unreasonably thin crust (Fig. $5 \mathrm{c}$ )

Fig. 6 displays the total and the filtered (wavelengths $<200$ $\mathrm{km}$ removed) residuals (observed free air anomaly - calculated anomaly) obtained with the direct models. Fig 6a shows the residuals for one of the $500 \mathrm{~km}$ profiles. Curve $a_{1}$ shows the residual obtained with a flexure model and curve $a_{2}$ the residual for an Airy II type of compensation. For a low rigidity plate model $\left(2 \mathrm{~km}\right.$ ), the residuals (curve $a_{1}$ ) are very close to zero (total residual rms $6.1 \mathrm{mgal}$; filtered residual $\mathrm{rms} 2.4 \mathrm{mgal}$ ) and most of the short wavelengths are well modeled. Some very high frequency signal is probably related to either the one-dimensionality of the model or to lateral density variations. A positive residual, comparable to the long wavelength of the observed signal, still exists. This is an indication that either the crustal thickness required by the flexure models to compensate the topographic load is too large or that the densities assumed are too high. The residuals (curve $a_{2}$ ) obtained for a model assuming an Airy II compensation with the density anomaly 4 to $8 \mathrm{~km}$ below the crust, as indicated from the admittance results, are stronger for the short wavelengths, but the long wavelength residual associated with the swell is well accounted for (total residual $\mathrm{rms} 10.9 \mathrm{mgal}$; filtered residual rms $1.5 \mathrm{mgal}$ ). A slight negative residual is probably associated with some flexural compensation of the larger topographic features which was not considered in the model. Fig. $6 \mathrm{~b}$ shows the model for the en-echelon ridge, with a local compensation (no rigidity, classical Airy model). The residual close to zero (rms $3.8 \mathrm{mgal}$ ) confirms that these features were created on a weak lithosphere. Fig. $6 \mathrm{c}$ presents the residuals (total residual rms $6.8 \mathrm{mgal}$; filtered residual $\mathrm{rms} 0.8 \mathrm{mgal}$ ) for a composite model for the $500 \mathrm{~km}$ profiles, considering a local compensation for the short wavelength topography $(1-200 \mathrm{~km}$ waveband) and an Airy II compensation for the swell $(\lambda>200 \mathrm{~km})$, with constant crustal thickness and a low density zone within the lithosphere. This is a more realistic model, and the long wavelength residual is very close to zero ( $\mathrm{rms} 0.8 \mathrm{mgal}$ ).
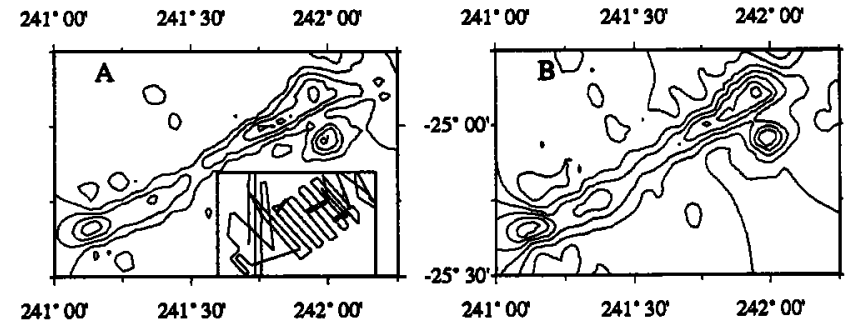

Figure 2. En-echelon ridge bathymetry (2a) and corresponding free air anomaly (2b). Survey lines are shown in inset. 

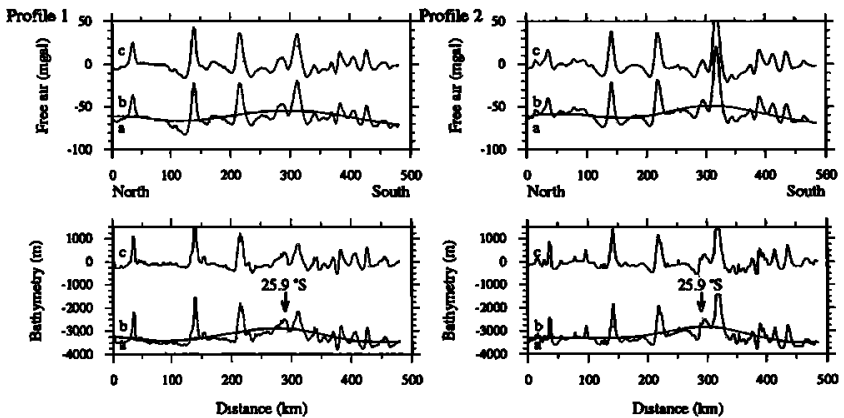

Figure 3. $500 \mathrm{~km} \mathrm{~N}-\mathrm{S}$ profiles: a) unfiltered, b) filtered (wavelengths shorter than $200 \mathrm{~km}$ removed) and c) residual (1$200 \mathrm{~km}$ waveband). On each graph, upper curves (c) display the short wavelengths and lower curves ( $a$ and $b$ ) the unfiltered signal and the long wavelength signal. Arrow shows the latitude at which the swell height is maximal.

\section{Discussion}

The existence of gravity and therefore geoid undulations of medium wavelength associated with a topographic swell between the Easter microplate and the Pitcairn hot spot has been confirmed. The results of the geoid modeling accord with the geodynamic setting of the area, a young lithosphere, deeply fractured by the proximity of the Easter microplate, and affected by long-lived thermal anomalies. The analysis of geoid profiles, covering a broader area integrating different tectonic provinces, tends to a result with a thin plate with an equivalent elastic thickness corresponding to the average age of the area. Results from the shipboard profiles indicate an Airy II type of compensation for the swell, with the topographic load being supported by a low density body lying at relatively shallow depths beneath a $8 \mathrm{~km}$ thick crust ( 4 to $8 \mathrm{~km}$ below the crust), rather than by a simple crustal thickening as in flexure models. Lithospheric ages range from 5 to $7 \mathrm{Ma}$ [Naar and Hey, 1991], corresponding to a thermal lithospheric thickness of $30 \mathrm{~km}$. The density anomalies would then be roughly halfway through the lithosphere, suggesting that the swell is probably related to a thermal/chemical anomaly close to the microplate and the Easter hotspot, with resulting density anomalies now embedded in the lithosphere. It has been argued that the apparent shallow depths of compensation generally observed for mid-plate swells could result from the presence of a low visco- sity layer below the lithosphere [Robinson et al., 1987]. Active convection in this layer could help to dynamically support the topography and create the gravity signal. The high viscosity contrast in the layer could mask the presence of density variations at greater depths. If active convection is present and contributing to the signal, the thickness of the low viscosity zone should be roughly of the same order as the wavelength of the gravity anomaly [Buck and Parmentier, 1986]. Also, we could expect some recent magmatic activity associated with the swell or with the superposed en-echelon ridges, as is the case for other mid-oceanic swells. A rock composition close to OIB basalts could also be expected. The petrological analysis of the rock samples dredged from the ridges shows that the composition of the basalts is close to volcanics from the southwest rift of the microplate and unrelated to other known South Pacific intraplate magmatism. The material is old and no trace of present day activity was found ( $R$. Hékinian, unpublished data). Our results for the en-echelon ridge indicate a very near-ridge emplacement on a weak and fractured lithosphere, confirming the hypothesis relating these features to the activity close to the southern border of the Easter microplate. The absence of recent magmatism and the petrology results strengthen the hypothesis relating the swell to a thermal/chemical anomaly located close to the Easter microplate and the Easter hotspot. Even if the presence of a low viscosity zone below the Pacific lithosphere is highly probable, the actual existence of active small-scale convection is still controverse and our results do not support this hypothesis.

\section{Conclusions}

The existence of geoid anomalies associated with the EasterPitcairn hotline is confirmed. The anomalies are related to a broad $(400 \mathrm{~km})$ topographic swell. Both results from admittance calculations and direct modeling indicate that the anomalies supporting the swell topography are located within the lithosphere, 4 to $8 \mathrm{~km}$ below the crust. The mechanism of compensation is compatible with the presence of a low density body in the upper mantle. The en-echelon ridges located on top of the topographic high show a local compensation in an Airy type mechanism, with thin crust. They are probably related to the southwestern border of the Easter microplate as well as to the Easter Island thermal anomaly and formed on a weak lithosphere. We cannot completely exclude a convective origin for the swell. It is possible that density anomalies created by convection near the microplate are frozen into the lithosphere. Also, the observed signal could be directly related to deeper convective rolls if a thick low viscosity zone exists,
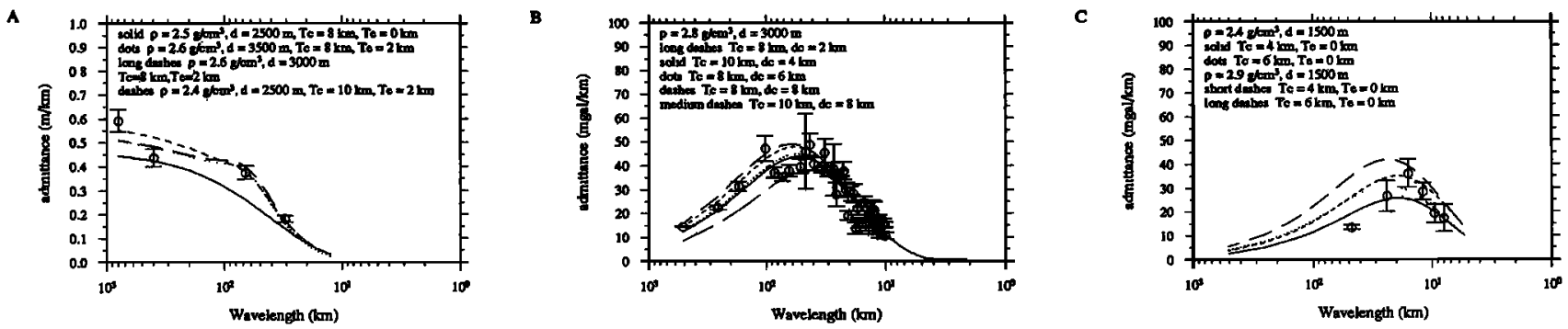

Figure 4. Admittance computed for the filtered geoid and synthetic bathymetric profiles (4a) the $500 \mathrm{~km}$ marine profiles (4b) and the ridge (4c). Curves show the fits for different compensation models. Te=effective elastic thickness; Tc=crustal thickness; $d c=$ depth of compensation (for Airy II models); $d=$ average depth of the topography; $p=$ average load density. For the $500 \mathrm{~km}$ profiles, only the fits for Airy II models are shown.
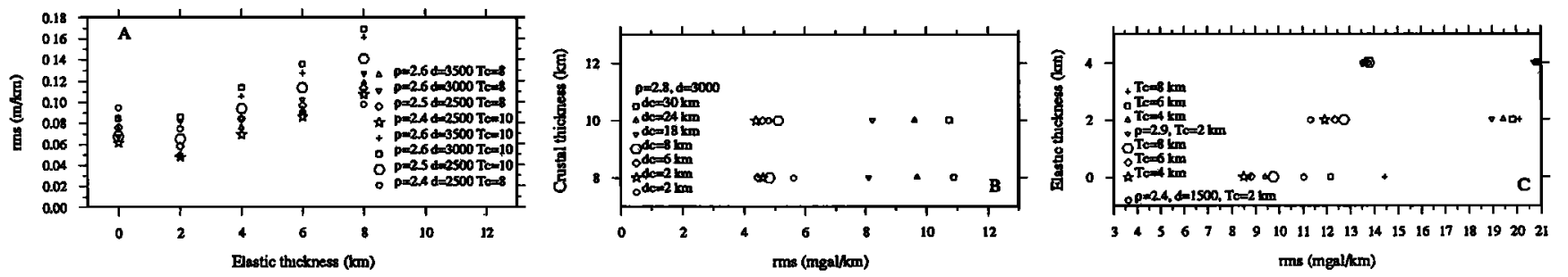

Figure 5. rms for the admittance fits for some of the considered models. For all figures, crustal thicknesses (Tc) and effective elastic thicknesses are in $\mathrm{km}$, average load densities $(\rho)$ are in $\mathrm{g} / \mathrm{cm}^{3}$ and average bathymetry depths (d) are in meters. $5 \mathrm{a}$ rms for the geoid admittances; $5 \mathrm{~b}$ rms for the $500 \mathrm{~km}$ marine profiles (dc is the depth of the density anomaly below the base of the crust in $\mathrm{km}$ ) and $5 \mathrm{c}$ rms for the en-echelon ridge profiles. 

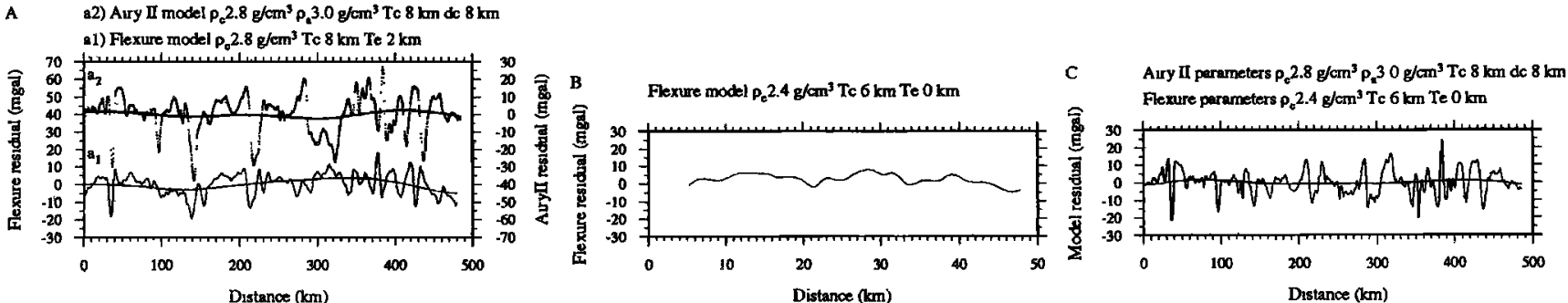

Figure 6. Residuals from the direct models (observed free air anomay - model anomaly). Curves correspond to the total residual and to the filtered (wavelengths $<200 \mathrm{~km}$ removed) residual (smooth lines). 6a. Models for the $500 \mathrm{~km}$ long profiles. Only one profile is shown. $\left(a_{1}\right)$ Airy II model, assuming a constant crustal thickness, with the Mobo interface following the swell topography and a low density $\left(\rho=3000 \mathrm{~kg} / \mathrm{m}^{3}\right)$ body in the upper mantle. The strong high frequency signal present in the total residual results from not considering any compensation model for the short wavelength topography. A sligth negative residual for the long wavelengths is still present and may correspond to a certain deflection of the lithosphere beneath the long wavelength topography. $\left(a_{2}\right)$ Flexure model, with a thin elastic plate $($ E.E.T. $=2 \mathrm{~km}$ ). The short wavelength topography is well accounted for, but the strong positive residual related to the topographic swell shows that flexure models alone are inadequate to explain the observed anomaly. 6b. Flexure (Airy model) total residual for the oblique ridge (average profile). The model predicts most of the observed signal, except for some small variations probably related to crustal density heterogeneities and the presence of sediments. 6c. Composite model for the $500 \mathrm{~km}$ profiles. The short wavelength $(1-200 \mathrm{~km})$ topography is modeled by a local compensation in an Airy sense and the long wavelength by an Airy II model, with constant thickness crust and low density in the upper mantle. The model accounts for the different processes that act in both wavebands.

but values of viscosity required to bring apparent compensation depths up to $12 \mathrm{~km}$ below seafloor would be very low. Such values could however result from the interaction of a complex accretion pattern and the Easter Island hotspot. The identification of superposed relative and absolute plate directions in the geoid anomaly pattern of the North Pacific (J.L. Olivet, pers. comm.) shows that at least in some parts of the Pacific, geoid undulations may be related to convection.

Based on our multi-scale analysis and on the petrological characteristics of the en-echelon ridges, we prefer the alternative hypothesis. The density heterogeneities were created by a regional thermal anomaly, resulting from the interaction of the Microplate accretion processes and the Easter Island hotspot.

Acknowledgements. We are indebted to Captain M. Kull and crew of the FS SONNE as well as to our colleagues of the Scientific Party for their help during the SO-80 cruise. Discussions with J.L. Olivet, R. Hékinian and C. Devey were very helpful. Comments of D. Gibert and two anonymous reviewers much improved this work. Figures were drawn using the GMT software of Wessel and Smith (1991). This work was funded by ATP Géosciences Marines (INSU) and by EEC contract $n^{\circ}$ CEE SC1 CT92 0782

\section{References}

Baudry, N. and L. Kroenke, Intermediate wavelength $(400-600 \mathrm{~km})$, South Pacific geoidal undulations: their relationslip to linear volcanic chains. Earth Plan. Sci. Lett., 102, 430-443, 1991.

Buck, W.R. and M. Parmentier, Convection beneath young ocanic lithosphere: implications for thermal structure and gravity. $J$. Geophys. Res., 91: 1961-1974., 1986.

Bonatti, E., C.G.A. Harrison, D.E. Fischer, J. Honnorez, J.-G. Schilling, J.J. Stipp and M. Zentilli, Easter volcanic chain (Southeast Pacifıc): a mantle hot line. J. Geophys. Res., 82, 2457 2475, 1977.

Cazenave, A., S. Houry, B. Lago and K. Domunh, Geosat-derived geoid anomalies at medium wavelengths. J. Geophys. Res., 97, 70817096, 1992.

Calgano, P. and A. Cazenave, Present and past regional ridge segmentation: evidence in geoid data. Geophys. Res. Lett., 20, $1895-$ 1998, 1993.

Diament, M. and N. Baudry, Structural trends in the Southern Cook and Austral archipelagoes (South Central Pacific) based on an analysis of SEASAT data: geodynamic implications. Earth. Plan. Sci. Lett., $85,427-438,1987$.
Haxby, W.F. and J.K. Weissel, Evidence for small-scale mantle convection from Seasat altimeter data, J. Geophys. Res., 91, 35073520,1986

Inoue, H., A least-squares smooth fitting for imegularly spaced data: finite-element approach using the cubic B-spline basis, Geophysics, 51, 2051-2061, 1986.

Louden, K., A comparison of the isostatic response of bathymetric features in the north Pacific and Philippıne Sea. Geophys. J. $R$ astr. Soc., 64, 393-424, 1981.

Maia, M. and M. Diament, An analysis of the altumetric geord in various wavebands in the central Pacific Ocean: constrants on the origin of intraplate features. Tectonophysics, 190, 133-153, 1991.

MacAdoo, D. and D. Sandwell, On the source of cross-grain lineations in the Central Pacific gravity field. J. Geophys. Res., 94, 93419352, 1989

Naar, D. and R. Hey, Tectonic evolution of the Easter Microplate. $J$. Geophys. Res., 93, 8735-8745, 1991.

Parker, R.L., The rapid calculation of potential anomalies. Geophys. J. R. astr. Soc., 31, 447-455, 1972.

Robinson, E., B. Parsons and S. Daly, The effect of a shallow low viscosity zone on the apparent compensation of mid-plate swells, Earth. Plan. Sci. Lett., 82, 335-348, 1987.

Smith, W., On the accuracy of digital bathymetric data. J. Geophys. Res., 98, 9591-9603, 1993.

Turner, D.L. and R.D. Jarrard, K-Ar dating of the Cook-Austral island chain: a test of the hot-spot hypothesis. J. Volcanol. Geotherm. Res., 12, 187-220, 1982.

Winterer, E.L. and D. Sandwell, Evidence from en-echelon cross-grain ridges for tensional cracks in the Pacific plate. Nature, 329, 534 . 537, 1987.

M. Maia and J. Francheteau, Université de Bretagne Occidentale, Laboratoire de Géophysique, Av. Le Gorgeu, BP 452, 29275, Brest cedex, France

G.A. Dehghani, Institut für Geophysik, Universität Hamburg, Bundestrasse 55, 20146 Hamburg 13, Germany

M. Diament, Institut de Physique du Globe, 4 Place Jussieu, 75252 Parıs cedex 5, France

P. Stoffers, Geologisch-Paläontologisches Institut, Chrıstıan-A1brechts-Universität, Olshausenstrasse 40,24118, Kiel, Germany

(Received: March 16. 1994; Revised: June 6. 1994;

Accepted: June 23. 1994) 